\title{
A comparative curricular review project
}

\author{
WILLIAM T. CROW, DO \\ JOAN CHRISTY, MS \\ DOUGLAS VICK, DO \\ JOHN R. PECKHAM, DO
}

This article describes a curriculum review project at the Texas College of Osteopathic Medicine. The authors used the Core Curriculum in Osteopathic Education as a standard of comparison of the comprehensiveness of the college's instruction in osteopathic philosophy, principles, and practices and to clarify any differences between the Core Curriculum document and the college curriculum. The process involved a courseby-course search by student physicians and was reviewed by course faculty. Results revealed that the college's coverage was very similar to that proffered by the Core Curriculum. However, there were areas of instructional redundancy, questions of sequencing, and a few topics not addressed within the college curriculum. Thereafter, the faculty consolidated several courses, which produced a net savings of weekly contact hours and allowed further curricular change. Particular attention was given to the manner in which the other courses were scheduled, and, in turn, the consistency and stability of the entire first year was improved significantly.

The Center for Osteopathic Research and Education (CORE) at the Texas College of Osteopathic Medicine (TCOM) has as its purpose spreading the four-year curricular program in application of osteopathic philosophy, principles, and practices throughout the TCOM curriculum. The CORE asked the authors to conduct a curriculum review project using the Core Curriculum in Osteopathic Education ${ }^{1}$ (produced by the Educational Council on Osteopathic Principles ECOP, which is an affiliate of the American Association of Colleges of Osteopathic Education), as a standard for comparison. The project was aimed at analyzing the comprehensiveness of the college's instruction in osteopathic philosophy, principles, and practices and at clarifying any differences between the ECOP document and the college curriculum. Before discussing the project methods and results, a brief overview of the two curriculums involved is appropriate.

\section{ECOP curriculum}

As indicated in the following excerpt from the ECOP Preamble ${ }^{1}$ the document is comprehensive in scope and integrative in nature:

In implementing the Core Curriculum, the dynamic interrelationship between knowledge of the key basic concepts and their application in patient evaluation and care must be emphasized. The osteopathic approach to health care is concerned with the interrelationships of human anatomy, physiology, and psychology (behavior) in a social and cultural environment. No matter how the basic principles and their application are sequenced in an outline, the teaching of the principles and their application should emphasize the dynamic interrelationship among them. Basic content, knowledge, and clinical material should be interwoven in the teaching of each region. The student should have the opportunity for personal clinical experience with the application of basic concepts and principles. This will reinforce the student's curiosity and interest in the basic science while helping to explain his or her experience and positively influence future patient care.

The Core Curriculum in Osteopathic Education ${ }^{1}$ has two major parts: Part I is an introduction and 
outline of fundamentals, and part II shows the application of principles in major body regions (Table).

\section{Table}

Outline of Core Curriculum in Osteopathic Education ${ }^{1}$

\section{PREAMBLE}

History and philosophy

(I) Historic and philosophic foundations for osteopathic medicine

(A) Concise history of the development of medical knowledge and practice

(B) Philosophy of osteopathic medicine

(C) Scientific basis for osteopathic medicineosteopathic research

(II) Health and illness from an osteopathic perspective

(A) Health-illness spectrum

(B) Patient management

(III) Biomechanical concepts

(A) Somatotypes

(B) Kinetics and biomechanics

(IV) Theory and development of musculoskeletal examination skills

(A) Observation

(B) Palpation

(C) Gross motion testing

(D) Muscle strength testing, grading, and muscle coordination

(E) Reproduction of characteristic pain by positioning movement and deep pressure

(V) Physiologic concepts and neuromusculoskeletal

functions

(A) Muscle physiology

(B) Neural control of muscle function

(C) Hormone and neurotransmitters and their effects on neuromusculoskeletal function

(D) Body framework physiology

(E) Physiology of pain

(F) Intrinsic mechanisms

(G) Nutrition and elimination in tissues

(H) Pathophysiology

\section{Fundamentals of patient evaluation and management}

(I) Definitions

(II) Patient evaluation
(A) History
(B) Physical examination
(C) Order, frequency, and type of treatment
(D) Indications and precautions
(E) Adjuncts to osteopathic manipulation
(F) Record-keeping

(III) Management plan for somatic dysfunction

(A) Purpose of treatment

(B) Approaches to osteopathic manipulative treatment

(C) Order, frequency, and type of therapy

(D) Indications and precautions

(E) Adjuncts to osteopathic manipulation

(F) Record-keeping

(IV) Clinical correlates

Application of osteopathic principles in body regions

(I) Head and neck

(II) Upper extremities

(III) Thoracic spine and costal cage

(IV) Lower extremities and feet
Part I has three sections. The section on history and philosophy lists the items that cover the development and philosophic foundations of the osteopathic profession. The second and third sections, fundamental concepts relevant to osteopathic medicine and fundamentals of patient evaluation and management, detail the basic science knowledge necessary to practice osteopathic health care and a general overview of the application of knowledge in the clinical setting.

Part II outlines present basic and clinical science concepts pertinent to a specific body region (for example, head and neck, thoracic spine and costal cage), as well as the application of basic knowledge to patient evaluation and management of that particular body region. Major subjects in part II include the following: anatomy of regions, including functional or clinically applied anatomy; physiology; patient evaluation and development of database; history-taking and physical examination for that body region; laboratory and special diagnostic studies; and differential diagnosis and case studies.

Thus, the Core Curriculum presents an integration of the disciplines basic to osteopathic medicine (organized according to musculoskeletally defined body segments) preceded by a clarification of philosophy and principles. It is an attempt to delineate what is unique about osteopathic medical education. However, it contains no references to the disciplines of disease, such as pathology or microbiology.

At the time of this project, the document was limited in three ways. First, it was a working document about the body from the head and neck down to the thoracic cage, with instruction about the remainder of the body regions still being compiled by ECOP. Second, by design, the ECOP curriculum did not include explicitly all of the curricular material presented in the courses at TCOM. Third, the document was not ratified by the colleges participating in its development, and, therefore, it served only as a framework from which the faculty and administration could build or review a curriculum. The document did not describe how the curriculum was to be implemented or in what sequence the material was to be presented.

\section{College curriculum}

The college curriculum of the first four semesters was characterized by an abundance of courses. In particular, it was composed of courses in the traditional basic sciences, patient skills, manipulative 
diagnosis and treatment, and a number of others aimed at broadening the student's perspective. The latter provided lectures and community service experiences in the areas of, for example, the history and evolution of the profession, the status of the health-care system and the professionals within it, and the tenets and methods of health promotion and community awareness, including delineation of specified populations requiring specialized healthcare services. These courses were designed to draw the student beyond the traditional doctor-patient, episodic, illness-care model of health care.

During the course of the review process, the authors came to refer to these courses as the social sciences of medical education. All in all, students were involved in approximately 10 to 12 courses at any given time. Thus, the curricular review process involved the comparison of the ECOP document to more than 20 courses presented to students in their first four semesters at TCOM.

\section{Study methods}

The review process involved a course-by-course search for each topic and its inherent subtopics in the ECOP document. Under faculty supervision, two students, who worked full-time during summer break, performed the review. One student had just completed his first year of medical school and the other, his second.

Course syllabuses, class handouts, lecture notes, and, on occasion, memory were all used to determine in which course and in what semester and month each item was addressed. To facilitate a systematic and consistent approach to the review process, one vertical column for each course was added to the right of the ECOP document items. Notations were made in the columns to indicate, by course, the semester and month during which the corresponding item was taught. The column notations represented actual lectures, or, in the case of alternative instructional methods, the time period during which the particular content area was emphasized in the course. In the event that the material was presented as a lecture and emphasized in class, the notation represented the lecture, and the time period (for emphasis) was noted in the comments section. If there was even a brief mention of the subject in a lecture or other instructional situation, the same notation was used as if there had been a formal lecture. Specific symbols were used to indicate when the presentation spanned across months, as opposed to when it was repeated in subsequent months.
Once the review of major contributing courses was complete, a copy of the annotated document was provided to each of the course directors or their representatives for review and correction.

\section{Results}

The findings revealed that there were very few content areas included in the ECOP document that were not covered in a portion of the college curriculum under study. Although the organizations of the document and the curriculum differed, coverage was found to be very similar. This finding affirmed the curriculum development efforts of the respective faculty and the curriculum committees. It suggested that the comprehensiveness of the curriculum was not a problem, but that the relationship of its courses was. In addition to providing to the course directors and their faculty the short list of ECOP topics and items not addressed in the TCOM courses, we reported four areas of findings that dealt with how the curriculum fit together.

The first finding involved ECOP content areas in which TCOM provided redundant instruction in the college curriculum. Instruction was considered to be redundant if the same topic area was addressed in three or more courses and if no allowance for previous instruction was evident in subsequent materials. Obviously, there is a line of distinction between cumulative reinforcement and unproductive redundancy. The purpose of the report, however, was to draw attention to specific areas so that course directors and teaching faculty could draw their own distinctions.

The second finding involved issues of sequencing instruction in related or similar content areas. Often, it was found that the application of a concept or modality was taught in a course in the fall, before the foundation and scientific basis was taught in another course the following spring. For instance, students were given an introduction to muscle physiology as a foundation to learning about somatic dysfunction and applying that to palpatory diagnosis months before they received information on muscle physiology in greater depth in the physiology course. While this issue may, on the surface, appear to be one of redundancy versus reinforcement, the underlying consideration was that of curricular sequencing.

A third area had to do with two types of missed opportunities. The first refers to ECOP material that was not taught anywhere in the curriculum, the second to instances in which concepts were taught in specific courses, but the reinforcement 
of these concepts did not appear to be emphasized as strongly in the curriculum as they were in the ECOP document. Although these areas were few in number, their individual significance was a matter for faculty consideration.

The fourth finding was that there appeared to be a difference in emphasis according to type of course. In the more traditional courses, including those in the basic sciences and in patient interviewing and examination, there was little evidence of integration of philosophy and principles. In the social science courses and in manipulative medicine training, the students received the majority of philosophy, principles, and practices instruction. We found a significant amount of redundancy in this group. There was no prevailing osteopathic and central theme noted between the manipulative medicine and social science courses and courses involving the basic sciences and clinical disciplines.

\section{Faculty response}

After review of the full report, the faculty developed a single series of three courses, as compared with more than ten courses previously taught during the first year. These included the courses found to be providing most of the instruction in osteopathic philosophy, principles, and practices. The consolidation involved first-year instruction in manipulative medicine, history-taking and physical examination, health promotion, medical humanities, and community awareness. The new series was arranged in the following manner:

The first course, an historical orientation to osteopathic health care and the osteopathic approach to patients, presented the evolution of osteopathic medicine. Osteopathic philosophy and principles, along with preventive aspects and measures by which osteopathic physicians could promote healthful behaviors among their patients, were introduced. Students were led to explore fundamental techniques of osteopathic manipulation and to look into patient populations whose needs extend beyond traditional medical care. Major emphasis was given to learning how to interact with patients and to obtaining information from them concerning their health problems and the life-styles that are inherent to those problems.

The second course, the osteopathic physician's approach to physical assessments, introduced the student to physical assessment of the patient, with physical examination and osteopathic assessment correlated by major organ systems wherever possible. Lecture presentations were coupled with prac- tice training sessions. In many sessions, students interacted with volunteer patients in the context of physical data collection. Clinical problem sessions were provided periodically to familiarize students with integrated data collection and presentation of patient findings. During this course, students also were introduced to acute-care life support and basic concepts of health promotion.

The third course, the osteopathic physician's approaches to intervention, presented the basic arguments and rationales as to the fundamental role of nutritional, manipulative medicine, and lifestyle modification in the development of a positive health strategy designed not simply to avoid disease but to promote health as well.

An important objective in this course was the development of decision-making strategy for improving health through diet and nutrition, articulation by thrusting and muscle energy manipulation, and life-style and behavioral changes. Students were involved in discussions concerning the practical problems associated with the development of such improvements.

The consolidation resulted in a net savings in weekly contact hours, which provided allowance for further curricular change. Particular attention was given to the manner in which the other courses were scheduled, and, in turn, the consistency and stability of the entire first year was significantly improved.

As this group of course directors review their courses now, they pay attention to areas of potential overlap and collectively manage their courses to maintain instructional efficiency, stability, and quality.

\section{Implications for other colleges and institutions}

Curricular review is at best difficult because it is hard to define what is taught, when it is taught, and whether more than one course includes the same material.

The easiest way to review a curriculum is on a course-by-course basis, usually in a cursory manner, because of a lack of time to do in-depth review. When an outside document such as the Core Curriculum is compared with an institution's curriculum, it can be reviewed osteopathically, by looking at the whole structure and the effects of each part on the whole. Student involvement in curriculum review is vital because students are the only ones who see the total curriculum and who, ultimately, are both consumers of the curriculum and products of the institution. 
In our experience, the Report on the Comparison of the ECOP Core Curriculum to the TCOM Curriculum of Years One and Two, ${ }^{2}$ from which this article was generated, became a starting point for small teams of faculty to sort out areas of redundant instruction and to plan changes in the sequence of material within a course.

Soon after this curriculum review took place, the college underwent an accreditation review. The accreditation team found the report to be helpful in its review process and encouraged further review into clinical didactics and rotations in the same manner.

For other colleges struggling with curriculum review, the process described is not difficult, but it is time-consuming. However, it does provide a wealth of information not available by any other means. The generation of such a review does not mean that a college has to change its methods of teaching or sequencing of courses. It only allows opportunity for the faculty to decide whether such changes are necessary. Also, it provides a unique overview to the total curriculum for both use by the faculty and accreditation review.

This type of review documents the effectiveness of integration of osteopathic principles, practices, and philosophy into the curriculum. The authors encourage other faculties to use the Core Curriculum and other such documents in a continual effort to improve osteopathic medical education.

1. Educational Council on Osteopathic Principles: Core Curriculum in Osteopathic Education. Educational Council on Osteopathic Principles Project on Osteopathic Principles Education, to be published..

2. Crow WT, Christy J, Vick D, et al: Report on the Comparison of ECOP Core Curriculum to the TCOM Curriculum of Years One and Two. Fort Worth, Tex, Center of Osteopathic Research and Education, Texas College of Osteopathic Medicine, to be published.

From the Center for Osteopathic Research and Education, Texas College of Osteopathic Medicine, Fort Worth.

Reprint requests to Dr Peckham, CORE, TCOM, 3500 Camp Bowie Blvd, Fort Worth, TX 76107. 